\title{
Doelwitbestuur: 'n Pragmatiese benadering
}

\author{
J.J. Murphy
}

Skool vir Bedryfsleiding, Universiteit van Suid-Afrika, Pretoria

\begin{abstract}
Management by objectives: A pragmatic approach. This article has a dual purpose. Firstly, the advantages associated with management by objectives (MBO) are outlined and the problems commonly experienced with implementation are highlighted. This part of the article is concluded by listing the eight key points that must be considered before any organization implements MBO. Secondly, 10 steps in the MBO process are discussed. These steps are considered within the context of the planning and control systems of the company or organization. This means that the MBO process is integrated with the planning and control systems of the organization.
\end{abstract}

S. Afr. J. Bus. Mgmt. 1982, 13: $136-141$

Die doel van hierdie artikel is tweêrlei van aard. Eerstens is dit om die voordele verbonde aan doe/witbestuur uit te stip en die gepaardgaande probleme van implementering aan te dui. Hierdie gedeelte word afgesluit met die agt sleutelpunte wat oorweeg moet word voordat enige organisasie doelwitbestuur implementeer. Tweedens word 10 stappe in die doelwitbestuursproses bespreek. Hierdie stappe word bekyk binne die konteks van die maatskappy of organisasie se beplanning en beheerfunksies; dit wil sê die doelwitbestuursproses word met die beplanning en beheerstelsels van die organisasie geïntegreer.

S.-Afr. Tydskr. Bedryfsl. 1982, 13: 136-141

\section{Dr. J.J. Murphy}

Skool vir Bedryfsteiding, Univer siteit van Suid-Afrika,

Posbus 392, Pretoria 0001, Republiek van Suid-Afrika
Gedurende die afgelope twee dekades het verskeie sogenaamde nuwe benaderings tot bestuur of nuwe konsepte te voorskyn getree en baie woorde is geskryf oor hierdie nuwe bestuurskonsepte. Byna al hierdie nuwe konsepte was 'revolusionêr'; elkeen was 'n metode wat alle bestuursprobleme sou oplos. Dit is dan ook geen wonder dat bestuur tot 'n punt gekom het waar hulle sê: 'Hier is weer 'n nuwe truuk. Ek wonder hoe lank dit sal wees voor daar weer iets nuuts is'. Doelwitbestuur is in die begin ook deur bestuur in hierdie lig beskou. Dit is egter ook waar dat dit vir daardie bestuur wat 'n deeglike studie van die rasionaal agter doelwitbestuur gemaak het, al gou duidelik geword het dat hier 'n tegniek was wat met vrug in die organisasie kon aangewend word en dat dit nie weer net 'n nuwe truuk was nie. Dit was werklik 'n nuwe en goedgefundeerde benadering tot bestuur, gebou op konsepte en beginsels wat reeds vir menige dekades in die bestuur van organisasies toegepas was. Inderdaad, menige van die beginsels en praktyke betrokke by doelwitbestuur is slegs dié wat in 'n mindere of meerdere mate deur goeie bestuurders toegepas is en word.

Wat doelwitbestuur inderdaad is, is slegs die sistematiese toepassing van hierdie basiese beginsels en funksies in 'n goedgestruktureerde stelsel. In sy mees doelmatige implementering is die resultate van doelwitbestuur die samevoeging en samehorigheid van alle mense betrokke in 'n stelselformaat. Prakties word dit so gedoen dat doelwitte en daardeur resultate bereik word wat vir sowel die organisasie as die individue van groot waarde kan wees.

\section{Reaksiebestuur teenoor doelwitbestuur}

Indien gekyk word na 'n kontinuum wat die verskillende benaderings tot bestuur voorstel (Figuur 1), is daar aan die een kant passiewe bestuur, of bestuur deur reaksie. Hier sien ons die bestuurder wat nie werklik weet wat gaan gebeur wanneer hy in sy kantoor instap nie; wat ookal sy lessenaar eerste bereik, wie die hardste skreeu, wat ookal die belangrikste lyk op daardie oomblik, dit is die aktiwiteit waarop hy sal reageer. Aan die ander kant van die skaal is doelwitbestuur. Hier het ons die bestuurder wat sy aktiwiteite vooraf beplan het, wat homself voorberei het vir elke moontlike afwyking en wat dus met die minste moontlike inspanning tog redelik beheer oor die aktiwiteite het en weet wat aangaan. Nie een van hierdie uiterste gevalle bestaan egter wel in die suiwerste sin nie.

Alle bestuurders bestuur by tye deur middel van 
Reaksie $\begin{array}{rr}1 & 1 \\ 1 & 1 \\ \end{array}$

Figuur 1 Bestuurskontinuum (1)

reaktiewe bestuur, dit wil sê hulle reageer op dinge wat plaasgevind het - want dinge vind wel plaas wat bestuur nie kan voorsien nie. Tog is dit ook so dat goeie bestuurders in 'n sekere mate wel daarin slaag om doelwitte te stel en dan te werk vir doelwitbereiking. Wat dus in die algemeen gebeur, is dat die meeste bestuurders 'n bestuurstyl of benadering het wat êrens tussen hierdie twee uiterste gevalle op die kontinuum lê. Die hoogs professionele bestuurder sal heel moontlik meer na die kant van die kontinuum werk waar doelwitbestuur is. Inderdaad het ons hier die verskil tussen die sogenaamde 'fire fighting' aan die een kant en die voorkoming van vuur aan die ander (Morrisey ${ }^{l}$ ).

In Suid-Afrika vind ons ongelukkig dat die sogenaamde 'heldbestuurder' dié een is wat ' $n$ fantastiese vermoë het om vure te blus. Baie minder erkenning word verleen aan die bestuur wat doelmatige beplanning gedoen het en dus verhoed dat die vuur in die eerste plek ontstaan. Dit is soos 'n welbekende Springbokstut eenkeer gesê het: "Sekere spelers speel vir die "grand stand" terwyl ander vir die spel speel'.

Dit bring ons by ' $n$ belangrike punt, naamlik dat indien doelwitbestuur suksesvol geïmplementeer wil word, die prestasiesisteem daarop ingestel moet wees om die bestuurder wat die krisis verhoed, te beskou as 'n baie doelmatige bestuurder; net soveel as die persoon wat die krisis kan hanteer. Dit wil nie sê dat die krisisbestuurder nie 'n baie waardevolle lid van die bestuurspan is nie. Elke bestuurder kom van tyd tot tyd in krisissituasies en die manier waarop hy die krisis hanteer, is van kardinale belang. Aan die ander kant is dit net so belangrik dat topbestuur moet weet dat hulle bestuurders baie hard en duidelik kyk na die organisasie en sy omgewing, en doelmatige beplanning uitvoer om krisisse so ver moontlik te verhoed.

\section{Voordele van doelwitbestuur}

Voordat daar gekyk word na die basiese elemente van doelwitbestuur, sou dit miskien goed wees om te let op die voordele wat doelwitbestuur vir organisasies inhou. Terselfdertyd moet daar ook gelet word op die uitdagings wat in die pad staan van effektiewe doelwitbestuurimplementering.

Humble 2,pp.12-16;3 skryf die volgende voordele aan doelwitbestuur toe: In die eerste plek sal die organisasie wat doelwitbestuur as 'n algemene bestuurswyse aanvaar, beter bestuursresultate verkry, dit wil sê 'n bestuurder sal meer en beter gebruik maak van die hulpbronne tot sy beskikking; dan ook nie in terme van sy individuele prestasie nie, maar in terme van die kollektiewe prestasie van al die hulpbronne tot sy beskikking.

Die tweede voordeel is daarin geleë dat doelwitbestuur 'n metode is om die 'Peter-beginsel' te verhoed. Dit is so dat baie bestuurders hulle vlak van onbevoegdheid bereik voordat die organisasie dit daadwerklik agterkom. Doelwitbestuur is ' $n$ metode om te verhoed dat sodanige persone wel die vlak van onbevoegdheid bereik.

'n Derde voordeel is dat beplanning eindresultaat- georiënteerd word. Die beplanning by doelwitbestuur is op die eindresultaat of die doelwit gerig en nie op die aktiwiteite wat aangegaan moet word nie. Edward Green het die stelling gemaak: 'Plans are useless but a planning process is invaluable'. Beplanning is 'n proses - en nie slegs die produksie van dokumente nie. Die ontwikkeling van 'n geordende beplanningsproses is die kenmerk van 'n suksesvolle bestuurder.

'n Vierde voordeel is direk gekoppel aan verbeterde beheer, dit wil sê, beheer in 'n bestuursin: beheer oor resultate eerder as beheer oor mense. Indien doelwitbestuur effektief in 'n organisasie geïmplementeer word, sal daar gevind word dat individue 'n groter mate van selfbeheer toepas aangesien hulle self weet wat verwag word as hulle hul deel bygedra het in die daarstelling van die doelwit. Indien individue gemotiveer is om verantwoordelikhede te aanvaar soos dit deur doelwitbestuur gepropageer word, is dit ' $n$ baie beter bestuursmetodiek as dié waar die bestuurder gedurig oor persone se skouers moet kyk om seker te maak dat dinge wel gedoen word. Dit lei logieserwyse tot verbeterde bogeskikte/ondergeskikte verhoudings, want deur middel van doelwitbestuur word daar aan die ondergeskikte erkenning gegee in dié sin dat hy weet wat hy doen, wat hy behoort te doen, wat sy bydrae is en dat hy erkenning kry vir sy werk. Dit bring bogeskikte en ondergeskikte baie nader aan mekaar aangesien hulle 'n gesamentlike betrokkenheid het by die werk wat gedoen moet word en dit bring op sy beurt weer verbeterde spangees en prestasie mee. Die stelling kan moontlik gemaak word dat werklike delegasie onmoontlik is in 'n organisasie sonder doelwitbestuur.

Daar is genoegsame getuienis in menige maatskappye dat die deelname verkry deur middel van doelwitbestuur goeie resultate vir sowel die organisasie as die individu lewer. Die grootste enkele voordeel wat na vore tree met die implementering van ' $n$ doelwitbestuurbenadering is waarskynlik dié van betrokkenheid. Indien iemand ' $n$ doelwit vir 'n ondergeskikte stel, is die werknemer se betrokkenheid baie laer as wanneer hy hierdie doelwit self geformuleer het. McGregor toon aan dat mense waarskynlik meer belangstelling in 'n organisasie se doelwitte sal toon, asook verantwoordelikheid sal aanvaar, indien hulle in die eerste plek 'n sê gehad het in die stelling van die doelwitte.

Daar is dus 'n verskeidenheid van voordele wat verkry kan word met die implementering van doelwitbestuur in 'n organisasie: beter bestuursprestasie; groter waarskynlikheid dat bestuurders op hulle vlak van bevoegdheid werk; verbeterde beplanning met meer klem op resuliate (verbeterde beheer oor resultate is beter as beheer oor mense); en 'n beter verstandhouding tussen bogeskikte/ ondergeskikte met 'n gepaardgaande verbeterde spanpoging.

Daar moet egter daarteen gewaak word dat doelwitbestuur nie ontaard in 'n monster nie. Heel dikwels gebeur dit dat topbestuur 'n seminaar bywoon of 'n artikel lees waarin die voordele van doelwitbestuur gepropageer word. Onmiddellik verklaar topbestuur dan deur middel van 'n memo dat die organisasie vanaf Maandag oor 'n week 'n doelwitbestuurstelsel sal volg. Die gesegde, ' 'n bietjie kennis is baie gevaarlik', is veral hier van toepassing. In baie gevalle beskou topbestuur doelwitbestuur as 'n metode waardeur hulle ondergeskiktes kan bykom indien hulle nie 
aan verwagtings v̀oldoen nie. Hierdie is 'n totaal verkeerde benadering tot doelwitbestuur; een wat doelwitbestuur tot mislukking sal doem.

\section{Implementering van doelwitbestuur: struikelblokke}

Moontlik die grootste uitdaging vir die doeltreffende implementering van doelwitbestuur is die aanvaarding van die feit dat dit harde werk sal verg. Die implementering van doelwitbestuur benodig deursettingsvermoë en die voordele is gewoonlik meer op die lang- as op die korttermyn sigbaar. Dit kan aanvaar word dat vir enige redelike groot organisasie, die implementering van doelwitbestuur in die orde van drie tot vyf jaar sal neem. Daar sal sekere korttermynresultate verkry word, maar die grootste betaling ('pay-off') sal op die langtermyn plaasvind. Ongelukkig is dit so dat bestuur oor die algemeen die opbrengs op belegging op die korttermyn wil sien en indien die implementering van 'n nuwe stelsel nie onmiddellke resultate lewer nie, verval hulle weer in die ou stelsels waaraan hulle gewoond is. Dit is dus duidelik dat een van die maniere om hierdie probleem te oorbrug, is om dit van die begin af duidelik te stel dat die implementering van doelwitbestuur 'n stadige proses is, dat dit opeenvolgend sal plaasvind en dat daar kritiese doelwitte gestel sal word wat van tyd tot tyd in die implementeringsproses geëvalueer moet word.

Nog 'n basiese probleem wat die implementeringsproses moet oorbrug, is die sogenaamde weerstand-teen-verandering konsep. In die algemeen werk bestuur baie eerder in stelsels of met stelsels waarmee hulle vertroud is en waarmee hulle 'n mate van sukses behaal het. Indien 'n nuwe stelsel op hulle afgedwing word wat hulle boonop nie verstaan nie, sal daar 'n weerstand wees teen hierdie implementering van die nuwe stelsel. Dit is dus duidelik dat, om hierdie sogenaamde weerstand te oorbrug, dit van die allergrootste belang is dat bestuur die stelsel begryp en aanvaar, en bewys lewer dat hulle dit self as 'n bestuurswyse aanvaar.

'n Verdere probleem met die implementeringsproses, wat saamhang met die veranderingsweerstand, is die kwessie van ingewikkeldheid. Prinsipieel, oftewel konseptueel, is doelwitbestuur baie eenvoudig, maar wanneer dit by die implementeringsproses kom, is dit baie makliker om oor doelwitte te praat en te skryf as om volgens doelwitte te bestuur.

'n Volgende belangrike struikelblok in die implementeringsproses is die kwessie van deurvoering. Menige stelsels wat deur die implementeringsprosesse gegaan het, het op die rotse beland deurdat hulle nie deurgevoer en opgevolg is nie. Die deurvoering, opvolging en veral die opvolgingsproses om te verseker dat die momentum wat verkry is, behoue bly, is van die allergrootste belang. Baie stelsels faal so: die bestuur spring weg met groot ywer en entoesiasme, maar met verloop van tyd vervaag entoesiasme, verflou ywer en gaan die momentum verlore; na sowat ses maande val die maatskappy weer terug in die ou prosedures.

Vir hierdie deurvoering en opvolgingsproses is dit dus duidelik dat topbestuur die stelsel moet aanvaar en steun. Dit moet nie net ondersteun word deur middel van lippetaal nie, maar ook deur aktiewe deelname aan die implementeringsproses. Indien ondergeskiktes sien dat topbestuur vir hulself doelwitte gestel het en daarvolgens werk en dat dit nie bloot lippetaal is nie, volg die implementering, opvolging en deurvoering baie makliker.

'n Verdere voorvereiste vir die implementering van doelwitbestuur is reeds bespreek, naamlik die koppeling van prestasiewaardering met aansporingskemas. Indien die ondergeskikte gemeet word in terme van die doelwitte wat gestel is en hy hierdie doelwit oorskry, is daar by hom 'n verwagting dat hy ooreenkomstig beloon of vergoed sal word. Hierdie vergoeding hoef nie noodwendig finansieel te wees nie, aangesien die vergoedingspakket uit verskeie elemente bestaan, maar die koppeling aan die prestasie en aansporing moet daar wees. Indien die organisasie die sogenaamde 'fire fighter' beloon en nie die persone wat 'n goeie taak verrig in terme van die doelwitbestuurstelsel nie, dan negeer bestuur die goeie insette wat hierdie bestuurder tot die doelmatige doelbereikingsfunksie van die organisasie verrig het.

Laastens, een van die groot beperkings op effektiewe doelwitbestuurimplementering is die gebrek aan opleiding in die prosesse van doelwitbestuur. Die lees van prosedurehandleidings en handboeke, seminaarbywoning, ens., is nie genoegsaam vir die implementeringsproses nie. Bestuurders moet deur middel van opleiding in al die fasette van die doelwitbestuurstelsel ingelig en onderrig word. Hierdie opleiding kan op verskillende vlakke plaasvind en verskillende spanne moet dus daarby betrek word. ${ }^{2,}$ pp.119-127

\section{Agt sleutelpunte vir oorweging}

In opsomming is daar sleutelpunte wat oorweeg moet word voordat enige organisasie doelwitbestuur implementeer:

- Dit vereis totale betrokkenheid van die organisasie.

- Dit neem tyd; die organisasie moet ingestel wees op die langtermyn- eerder as die korttermynvoordele.

- Dit verg deursettingsvermoë. Verandering, hoe voordelig ookal, is ongemaklik vir bestuurders of besture wat gewoond is aan bestaande tegnieke. Hulle moet oorgehaal en meegesleur word.

- Dit moet duidelik verstaan word dat die stel van doelwitte meer ingewikkeld is as wat dit met die eerste oogopslag sou voorkom.

- Dit vereis opvolging en deurvoeringsvermoë. Daar sal seker gemaak moet word dat progressiewe vooruitgang in die projek plaasvind en volgehou word.

- Dit vereis topbestuur se onderskraging. Topbestuur moet dit nie alleen onderskraag nie, maar moet ook 'n voorbeeld stel.

- Dit vereis ' $n$ direkte verbintenis tussen prestasiemeting en die beloningstelsel.

- Dit vereis opleiding, skoling en leiding in die proses van doelwitbestuur.

\section{Tlen stappe in die doelwitbestuursproses}

Tot dusver is gekyk na die voordele en die sleutelpunte wat in ag geneem moet word vir die implementering van ' $n$ doelwitbestuurstelsel in 'n organisasie. In die verdere bespreking van doelwitbestuur gaan ons van die veronderstelling uit dat die beplanning en beheerfunksies die kern van die basiese stelsel uitmaak. Ten opsigte hiervan moet die 10 basiese stappe in 'n doelwitbestuursproses dus gelys word. Voordat dit egter gedoen kan word, is dit noodsaaklik om eers die term doelwit duidelik te definieer. 
In die literatuur word verskillende definisies van doelwitte gegee. So byvoorbeeld praat Schutte. pp.53-54 van mikpuntdoelwitte asook operasionele doelwitte van die hoër en laer orde. Ander outeurs praat weer van doelstellings en doelwitte. Om verwarring te vermy sal daar in hierdie geskrif slegs van doelwitte gepraat word. Daar sal van 'n selfverklarende prefiks gebruik gemaak word om onderskeid te tref tussen die verskillende soorte doelwitte, byvoorbeeld bestaansreg- of kontinue doelwitte.

\section{Stap I: definiëring van bestaansregdoelwitte}

Met die eerste oogopslag sou hierdie 'n oortollige aksie blyk te wees. Die meeste werke of take van 'n organisasie word deur middel van 'n taakomskrywing ('job description') omskryf, met ander woorde wat in daardie besondere taak, funksie of area moet gebeur, word presies gedefinieer. Niemand sal egter verbaas wees indien dit gestel word dat in die organisasie wat vir ' $n$ aantal jare bedryf word, praktyke ontwikkel het wat sowel 'n vermorsing as duplisering is. In hierdie situasie word kritiese werk nie gedoen nie; aan die een kant omdat aanspreeklikheid vir prestasie nie spesifiek aan iemand gekoppel was nie, of, aan die ander kant, omdat daar 'n verandering was in die organisasie se oorhoofse doelwit wat sekere take nodig gemaak het en hierdie take dus nie meer van toepassing is nie. Verder, in menige organisasie bestaan situasies waar die werknemers en, onder sekere omstandighede bestuurders, geen verwantskap kan sien tussen wat hulle doen en die klaarblyklike rede vir die bestaan van die organisasie nie.

Meer krities nog, bestaan die moontlikheid dat aansienlike energie aangewend word in werksaktiwiteite wat weinig of geen bydrae tot die organisasie se winsgewendheid of ekonomiese welvaart lewer nie. Dus is die hoofbeweegredes vir die bepaling van die bestaansregdoelwitte van 'n gegewe organisasie en/of van funksionele eenhede

- om die aanspreeklikheid vir resultate te bepaal en vas te lê,

- om 'n duidelike uiteensetting te gee van die werk van 'n besondere eenheid, en

- om die verwantskap tussen sodanige eenheid en die totale organisasie, te bepaal.

Dit beteken die definiëring en neerskrywe van die spesifieke bydrae wat deur elke bestuurder in die organisasie tot die oorhoofse doelwit van die maatskappy gelewer word in soverre dit ekonomiese, funksionele en sosiale verpligtinge aangaan, asook van die hoof-tipes werk wat hierdie besondere eenheid moet verrig in die uitvoering van hierdie bydraes. So 'n definisie is die logiese beginpunt vir die bepaling van ander eenheidsdoelwitte.

Dit is duidelik dat dit heel dikwels gebeur dat 'n verandering in fokus of strategie van die maatskappy 'n groot effek op die verwagte funksies of take van individue binne die organisasie mag hê. 'n Voorbeeld hiervan is Krygkor. Krygkor se verrigtinge is oorspronklik gesien as 'n aankopefunksie vir die Suid-Afrikaanse Weermag. As gevolg van die wapenboikot het hierdie funksie egter mettertyd uitgebrei tot waar dit nou produksie en die skepping en totstandkoming van produksiefasiliteite insluit. Dit het tot gevolg gehad dat baie van die funksies van Krygkor totaal verbreed of vergroot het en dat ' $n$ hele aksentverskuiwing binne die Krygkor-opset plaasgevind het. Die verandering vanaf $k$ waliteitsbeheer tot $k$ waliteitsverseke- ring in 'n groot Suid-Afrikaanse onderneming het ' $n$ heel nuwe struktuur teweeggebring. Dit is dus duidelik dat daar voortdurend na sowel die definiëring van die bestaansreg. doelwitte van organisasies as na funksionele werkeenhede gekyk moet word in terme van veranderings wat in die omgewing en in die organisasie plaasgevind het.

\section{Stap 2: kontinue doelwitte}

In enige organisasie en/of departement of afdeling bestaan daar sekere kontinue doelwitte. Indien so 'n departement of afdeling ' $n$ bestaansreg het, beteken dit dat sekere funksies op 'n kontinue basis uitgevoer moet word. Die kwaliteitsinspekteur moet die kwaliteitsbeheerfunksie uitvoer, die produksiebestuurder moet $x$ eenhede produseer om kapasiteitsbenutting te verseker, ensovoorts. Hierdie kontinue doelwitte is egter nie staties van aard nie, maar is afhanklik van faktore soos:

- kapasiteitsbenutting

- hulpbron-doeltreffendheid

- die leer-kurwe

- eksterne omgewing.

Indien aanvaar word dat die organisasie op die kort termyn sou voortgaan met sy werksaamhede soos in die verlede, dan is die bepaling van die kontinue doelwitte afhanklik van:

- 'n meganistiese vooruitskatting en

- 'n analitiese vooruitskatting.

Met 'n meganistiese vooruitskatting word die sisteem as geslote beskou en word die verlede geëkstrapoleer tot die toekoms. Dit word dus aanvaar dat die status quo behoue bly en dat enige tendense wat hulself reeds openbaar het, sal voortduur.

Die analitiese vooruitskatting, daarenteen, is daarop gemik om die stelsel oop te maak vir die invloede van eksterne faktore. Die term ekstern kan beteken ekstern tot 'n besondere departement se eie grense, maar nog binne die organisasie se grense, sowel as ekstern tot die organisasie as geheel, byvoorbeeld sosio-ekonomiese asook politieke faktore en hulle effek op die organisasie.

Dit is nodig dat albei soorte vooruitskatting gemaak word om die basislyn van werksaamhede te bepaal. Anders gestel, die vooruitskattings is die bepalende faktore in die daarstelling van die kontinue doelwitte. ${ }^{5,6}$

\section{Stap 3: bepaling van verbeteringsdoelwitte}

Dit is duidelik dat, as gevolg van die sogenaamde leer- en momentumkurwes, bestuur daarop ingestel is om verbeterings te bewerkstellig deur middel van die sogenaamde 'strek'('stretch')-beginsel. Volgens hierdie beginsel moet elke persoon 'n uitdaging tot prestasie hê. Derhalwe word doelwitte gestel wat hoër is as wat die vooruitskatting aangedui het en as wat in die kontinue doelwitte vasgelê is. Dit is dus duidelik dat hierdie verbeteringsdoelwitte deur bestuur op die kontinue doelwitte gebaseer word.

Bestuur gaan van die veronderstelling uit dat die toekoms nie soos die verlede gaan wees nie en dat bestuur daadwerklike veranderings en verbeterings kan teweegbring in die organisasie se strewe na wins of prestasie. Hierdie verbeteringsdoelwitte kan dus ook beskrywe word as inkrementele doelwitte. Ons het dus die kontinue doelwit met, bygevoeg, die inkrementele of verbeteringsdoelwit. Onthou egter dat sulke doelwitte realisties moet wees en 
daarop ingestel is om ' $n$ realistiese 'strek' te gee van wat moontlik in die nuwe tydvak bereik kan word. (Doelwitte moet nie gesien word as iets waarmee ek myself in aansien kan verhoog by bo- of ondergeskiktes nie.)

Doelwitte, soos reeds gestel, is die begin sowel as deel van die beplanningsproses. Die neerskryf van die doelwit is om individue te help om hulle taak as bestuurders meer doeltreffend te verrig. Die konsensieuse bestuurder wat die identifikasie van doelwitte benader deur middel van 'n goeie analise sal in hierdie gevalle uitstaan bo dié wat doelwitte slegs op 'n lukrake wyse daarstel. 2, pp.80-81;6

In die neerskryf van doelwitte moet op twee basiese beginsels gelet word.

- Eenvoud - hoe minder woorde in die doelwitstelling gebruik word hoe doeltreffender is die doelwitstelling. Hoe meer woorde ons byvoeg, hoe komplekser word die stelling en hoe minder verstaanbaar. Die neerskryf van doel witte moet nie 'n spel word nie. Dit is ' $n$ uitdaging en 'n kans om inligting só te stel dat die persone wat daarmee moet werk, dit duidelik kan verstaan en weet waarna gestreef word.

- Dit bring die tweede beginsel, naamlik dat doelwitte nie absoluut verdedigbaar in die oë van alle wesens is nie. Dit is primêr ' $n$ kommunikasie-instrument vir die persone in die organisasie wat daarvan moet weet, met ander woorde dit is in die eerste instansie die individu en sy bogeskikte en in die tweede instansie die individu en sy ondergeskikte wat duidelikheid moet hê oor die doelwitte. Dit dien as 'n kommunikasiemiddel tussen hierdie drie partye en as hulle dit duidelik verstaan, is dit nie nodig dat hulle dit teenoor enige bestuurder in ' $n$ ander departement hoef te verdedig nie.

In die lynhiërargie van byvoorbeeld bemarking, kan duidelik by die ineenskakeling van doelwitte gesien word hoe ' $n$ doelwit-hiërargie vorm wat uiteidelik tot die bemarkingsdoelwit lei. Of enige iemand anders buite hierdie lynhiërargie van bemarkingsbestuur dit verstaan, is werklik nie van groot belang nie. Dit is 'n kommunikasiemiddel tussen die bemarkingsfunksionarisse.

Doelwitte begin gewoonlik met die woorde 'om' en bevat gewoonlik 'n datum, 'n koste en 'n resultaat wat bereik moet word - byvoorbeeld om 'n produk A te produseer teen R50 000 teen die middel van Junie. Hier het ons die woord 'om' gevolg deur 'n produk wat gemaak moet word, die koste verbonde, asook 'n tydbeperking. Hierdie doelwit, soos hierbo gestel, is baie duidelik een van die inkrementele of verbeteringsdoelwittipes; dit word gewoonlik deel van 'n aksieprogram of, anders gestel, uiteengesit in 'n aksieprogram waarin nie alleen die tyd, produk en koste nie, maar ook die finansiële implikasies of winsimpak van so 'n program aangedui word.

\section{Stap 4: spesiale doelwitte}

Onder spesiale doelwitte moet verstaan word doelwitte bo en behalwe die normale werksaamhede van die departement or organisasie. So byvoorbeeld kan bestuur verwag dat die personeelafdeling, bo en behalwe hulle normale werksaamhede, 'n ondersoek moet loods en rapporteer oor byvoorbeeld die organisasieklimaat. Dit is belangrik dat spesiale doelwitte ook geformuleer en op die doelwithiërargie van die organisasie aangebring word.

\section{Stap 5: programmering}

Met hierdie stap word die aksieplanne uitgewerk waarvolgens die doelwit bereik moet word. Nadat die doelwit gestel is, word die doelwitbereikingsaksie opgebreek in kleiner bereikbare stappe en geprogrammeer deur middel van aksieprogramme. Die voltooiing van hierdie aksieprogramme moet noodwendig lei tot doelwitbereiking. Mali ${ }^{7}$ verskaf goeie riglyne oor hierdie belangrike aspek van doelwitbestuur.

\section{Stap 6: skedulering}

Hierdie stap behels die skedulering of bepaling van die tyd en volgorde benodig vir doelwitbereiking. Skedulering is ' $n$ indirekte deel van die totale proses tot dusver aangegee. Dit is op hierdie besondere punt waar die kalenders in ag geneem moet word vir elke spesifieke doelwit en elke spesifieke program en programstap.

\section{Stap 7: begroting}

Wanneer die beplanning van die wyse waarop die doelwitte bereik gaan word deur middel van die aksieprogramme reeds uitgewerk is, word die finansiële implikasies daarvan omskep in ' $n$ begroting. Die begroting is dus die finale stap in die beplanningsproses en is dus, in der waarheid, die formalisering van die beplanning. Dit is op hierdie stadium dat die hulpbronne in terme van man-ure, materiaal, fasiliteite, uitrusting, ens. aangedui en in die begroting ingebring moet word. Die belangrikheid van hierdie stap is voor-die-hand-liggend in dié sin dat kostevoordeel- of kostedoeltreffendheidsanalises gedoen kan word in terme van verskeie alternatiewe. Tweedens, nadat die begroting opgetrek is, dien dit natuurlik as die bedryfsbeheerinstrument. ${ }^{4,}$ pp.71,83

\section{Stap 8: standaardvasstelling}

Dit is duidelik dat die bepaling van standaarde ' $n$ inherente deel van doelwitbestuur moet wees. So moet daar bepaal word watter faktore gemeet moet word om as indikatore van doelwitbereiking te dien. Standaarde word nie slegs gebruik om doelmatigheid (doelwitbereiking) te meet nie, maar ook doeltreffendheid (teen watter koste). In die meeste gevalle is standaardvasstelling vir die lynfunksies relatief eenvoudig aangesien dit kwantifiseerbaar is. Die probleem ontstaan egter by die staffunksies. So byvoorbeeld is dit relatief moeilik om standaarde te bepaal vir die prestasiemeting van die bestuurder: industriële verhoudinge.

Die bepaling van standaarde kan op verskeie maniere gedoen word. In die algemeen kan drie groepe onderskei word:

- direkte meting deur middel van waarneming

- direkte meting deur middel van berekeninge

- indirekte meting deur middel van indikatore.

As breë riglyn kan gekonstateer word dat doelmatigheid deur middel van indirekte meting gemeet word, terwyl doeltreffendheid deur middel van direkte meting gemeet word.

\section{Stap 9: meting en verslagdoening}

Dit is aksiomaties dat meting en verslagdoening ' $n$ inherente funksie van doelwitbestuur moet wees. Die beheeren verslagdoeningstelsel bestaan basies uit vyf komponente, 
naamlik:

- verslagdoeningstruktuur

- standaarde-toepassing

- prestasiemeting

- beplanning en skedulering

- standaardevaluering.

Die meting- en inligtingstelsel behoort uitsette te genereer wat aanpas by dié verskillende komponente.

Daar moet onthou word dat een van die groot probleme in die beheerproses dikwels is dat daar meer tyd en energie bestee word aan die rapportering van aktiwiteite as aan die uitvoering van dié aktiwiteite. Die bestuurder moet in staat wees om prestasie te meet teen die minimum tyd en koste. Tabel 1 toon die verskillende jaarlikse koste aan wat dit neem om verslagvorms in te vul: gegewe 'n arbeidstarief per uur teenoor die aantal minute wat dit neem om die verslag in te vul.

Tabel 1 Jaarlikse verslagdoeningskoste: arbeidstarief/uur geneem teenoor minute/dag/jaar

\begin{tabular}{crrrrr}
\hline \multirow{2}{*}{$\begin{array}{c}\text { Arbeidskoste/uur } \\
\text { in Rand }\end{array}$} & 4 & 8 & 12 & 16 & 20 \\
\cline { 2 - 6 } & 51 & 105 & 156 & 207 & 260 \\
3 & 58 & 140 & 208 & 276 & 346 \\
4 & 85 & 175 & 260 & 346 & 433 \\
5 & 102 & 210 & 312 & 414 & 520 \\
6 & & & &
\end{tabular}

\section{Stap 10: korrektiewe aksie - herbeplanning}

Doelwitbestuur is nie 'n eenmalige funksie wat met die jaarlikse beplanning geskied nie: dit is ' $n$ kontinue proses wat as gevolg van die meting-en verslagdoeningsfunksie weer en weer herhaal word. Met gereelde tussenposes, afhangende van die tydhorison van meting en verslagdoening, word die siklus van

- wat wil ek bereik aan die einde van die periode?

- wat het ek tot dusver bereik?

- wat gaan ek bereik aan die einde van die periode?

- wat kan ek doen om aan die einde van die periode te bereik wat ek wil bereik?

weer deurgegaan.

\section{Slot}

Ten slotte moet dit herhaal word dat, nieteenstaande die konseptuele eenvoudigheid van die begrip doelwitbestuur, dit nie maklik is om dit suksesvol te implementeer nie. Daar moet ook nie gedink word dat, indien die stappe hierbo aangetoon suiwer meganies uitgevoer word, dit sukses sal verseker nie.

In die laaste instansie is ' $n$ bestuurder se vermoë om kreatief te wees en om gesonde oordeel aan die dag te lê van deurslaggewende belang. 'n Bestuurder wat nie hierdie twee fundamentele elemente in sy mondering het nie, sal nooit werklik die top van die mas bereik nie. Wat doelwitbestuur wel kan doen, is om die gemiddelde bestuurder 'n beter bestuurder te maak.

\section{Summary}

This paper is an attempt to show:

- the advantages of implementing an MBO system

- the problems associated with implementing an MBO system

- the key areas which should be taken into consideration when implementing an $\mathrm{MBO}$ system, and

- the sequential but interactive and iterative phases of the MBO process.

One of the greatest advantages of the MBO system is that it focuses on results rather than activities. It is thus a mechanism whereby management by reaction (crisis management) is augmented by a more pro-active and innovative approach.

$\mathrm{MBO}$, although conceptually very simple, is in practice much more difficult to implement than it would seem. Some of the reasons for this are the pressure by top management for short-term results, the resistance-tochange syndrome and the question of perseverance. These and other difficulties are discussed in this article.

There are eight key areas that should be taken into account before the implementation of a MBO system. These are also discussed briefly in this article.

The final part of the paper concentrates on the sequential but interactive and iterative phases of the MBO process. It should, however, be realized that the MBO system is a subsystem of the management system and it is therefore necessary that we look at the $\mathrm{MBO}$ process within the context of the planning and control functions of the organization. (Although the motivational functions of management - leading and organizing - are equally important, for our purposes we are only interested in the planning and control functions of management.)

As all planning is objective-oriented, particular attention is given to the various kinds of objectives inherent in an MBO system. In this regard we discuss purpose objectives, continuous objectives, improvement objectives and special objectives. The logical steps of programming, scheduling and budgeting as related to objective achievement is also briefly touched on.

The paper ends with a short discussion on the setting of standards (as opposed to objectives) and the control and reporting function as related to the management-byobjectives approach.

\section{Verwysings}

1. Morrisey, G.L. Management by Objectives and Results. AddisonWesley, 1970, pp.2-3.

2. Humble, J. Improving Business Results: The Definitive Work on Management by Objectives. New York: McGraw-Hill, 1968.

3. Humble, J. How to Manage by Objectives. New York: Amacom, 1978, pp. $37-39$.

4. Schutte, F.G. Integrated Management Systems, Pretoria: Butterworths S.A., 1981.

5. Argenti, J. Systematic Corporate Planning. London: Thomas Nelson \& Sons, 1974, pp.77-80.

6. Wilson, S.R. \& Tomb, J. Improving Profits through Integrated Planning and Control. Englewood Cliffs, NJ: Prentice Hall, 1973, pp.31- 42 .

7. Mali, P. Managing by Objectives. An operating guide to faster and more profitable results. Wiley Interscience, (John Wiley, NY), 1972, pp.140-168. 